\title{
INVESTIGATION ON GEOMETRICAL PARTICLE PARAMETERS AND AERODYNAMIC FEATURES OF GRANULAR MANURE FERTILIZERS
}

\author{
Egle Jotautiene, Vaidas Bivainis, Karolis Zokaitis, Raimonda Zinkeviciene \\ Aleksandras Stulginskis University, Lithuania; \\ Egle.Jotautiene@asu.lt
}

\begin{abstract}
About 80 percent of organic biodegradable waste originates from agriculture. Valuable fertilizer is produced by recycling and organic waste is utilized. Most manure is accumulated in the farms of cattle. One way of such manure handling is to use them as secondary raw material utilization in the processing of organic products (fertilizer) graining. This paper provides the research results of granular manure compost fertilizer use and theoretical spread by standard fertilizer spreading equipment. For the research two different size granular organic compost fertilizers were used. There were investigated the particle geometrical parameters and aerodynamic features of granular organic compost fertilizers, estimated the critical particle velocity, flow rate coefficient and other parameters. A theoretical model was developed, which predicts the trajectory of individual fertilizer particles off-the-disc. The model presented herein requires validation with the data obtained from spreading tests. It was found that the organic granular fertilizer flow rate coefficient depends on the pallet diameter. For larger diameter pallets the flow rate coefficients are lower (Manure I, $K_{\text {sAvg }}=0.32 \mathrm{~s}^{-1}$ ), and for smaller diameter pallets a larger flow rate coefficient is needed (Manure II, $K_{s A v g}=0.37 \mathrm{~s}^{-1}$ ). After creation of the Finite element model (FEM) pellet aerodynamic and ballistic models the aerodynamic characteristics were received that can be used in selecting the spreading technological parameters.
\end{abstract}

Keywords: granular manure fertilizer, aerodynamic features, spreading.

\section{Introduction}

About 80 percent of organic biodegradable waste originates from agriculture [1]. Valuable fertilizer is produced by recycling and organic waste is utilized. Due to the constriction of the EU and Lithuania's environmental and ecological requirements the focus increases on disposal of waste formed through the farming process [2]. The largest livestock complexes have a lot of problems with the use of accumulated manure. 11-12 million tons of manure are formed in Lithuania. Most manure is accumulated in cattle farms (88.8\%) [1]. There are a lot of complaints from the surrounding residents due to the fact that manure emits an unpleasant odor stored in tanks for several years. One way of such manure handling is to use it as secondary raw material in the processing of organic products (fertilizer) graining [3]. These fertilizers are the best and most appropriate products for fertilizing. It is also the least hazardous fertilizer for the environment.

For the cylindrical granular organic scattering (to distribute on the soil), a centrifugal mineral fertilizer distributor can be used. This fertilizer distributor is designed for mineral fertilizer application. However, aerodynamic properties of the granular organic fertilizer differ from the spherical mineral fertilizers [4]. Difference in shape, the organic matter is usually of 4-6 mm diameter cylindrical shape. Aerodynamic drag coefficient of the cylindrical shape fertilizer differs about 3 times from the fertilizer of spherical shape. The density of the organic granules is also different from the mineral. This is the most influencing factor of the aerodynamic properties of the granular fertilizer and at the same time the quality of the application. Uneven fertilizer application affects the overall crop yield. In addition, it reduces the efficiency and profit margin, increases nutritional losses and environmental risks [5;6]. Although organic animal origin fertilizer pellets already have been examined, further comprehensive research is needed to set the technical parameters for the fertilizer $[3 ; 7]$. These comprehensive researches should be conducted by combining the key indicators: the fertilizer rate, compartment with, the application uniformity of the fertilizer.

The aim is to analyze and evaluate the aerodynamic features of granular organic fertilizers by experimental and numerical studies through the granular spreader simulation model, which simulates the sprinkled pellets spreader.

\section{Materials and methods}

The object of research is a distributor of granular organic fertilizer from agricultural waste products (poultry manure). Granular organic fertilizers are produced from natural materials. Organic fertilizers contain the biologically active nutrients: nitrogen, phosphorus, potassium, calcium, trace 
elements, and amino acids. These nutrients are more easily absorbed by plants. Furthermore, they significantly improve the soil chemical status, increase the humus content as well as increase the harvest and quality of plant development. The granular fertilizer characterizing indicators are shown in Table 1.

The diameter and the length of the pellets were set by using the electronic caliper (accuracy error $0.01 \mathrm{~mm}$ ). To set the length and diameter of the pellets randomly selected 500 pellets were taken. Also the average values were evaluated.

The aerodynamic properties of the pellets were established by using the test stand - classification K- 293, air flow meter Delta OHM DO 9847 (tolerance $\pm 0.1 \mathrm{~m} \cdot \mathrm{s}^{-1}$ ) and electronic scales IPC 3WP $( \pm 0.01 \mathrm{~g}$ accuracy). The test was performed by using the technique described in more detail in the source [3]. The test was repeated five times. The average number (the value was expressed as percentage) of repetitions was calculated from the results obtained for each air flow rate. The results of the test were processed with the Microsoft Excel Anova program.

Table 1

The main properties of granulated manure $[8,9]$

\begin{tabular}{|c|c|c|}
\hline Properties & Manure I & Manure II \\
\hline Quantity of dry material, $\%$ & 88 & 90 \\
\hline Density, $\mathrm{kg} \cdot \mathrm{m}^{-3}$ & 700 & 650 \\
\hline Ratio of C/N & 9 & 8.5 \\
\hline $\mathrm{PH}$ & 6.4 & 7 \\
\hline $\mathrm{N}, \%$ & 4.2 & 4 \\
\hline $\mathrm{P}_{2} \mathrm{O}_{5}, \%$ & 3 & 3 \\
\hline $\mathrm{K}_{2} \mathrm{O}, \%$ & 2.8 & 2.5 \\
\hline $\mathrm{MgO}, \%$ & 1 & 1 \\
\hline $\mathrm{CaO}, \%$ & 9 & 9 \\
\hline $\mathrm{Fe}, \mathrm{mg} / \mathrm{kg}$ & 1000 & 700 \\
\hline Pellet diameter, mm & $5-6$ & $4-5$ \\
\hline
\end{tabular}

The average pellet flow rate coefficient $K_{\text {sAvg }}$. was calculated in accordance with equation [3]:

$$
K_{\text {sAvg. }}=\frac{g}{v_{\text {nAvg. }}^{2}},
$$

where $g$-gravity acceleration, $\mathrm{m} \cdot \mathrm{s}^{-2}$;

$v_{n}$ Avg. - average critical air flow velocity, $\mathrm{m} \cdot \mathrm{s}^{-1}$.

$$
v_{n A v g .}^{1}=\frac{v_{1} m_{a}+v_{2} m_{a}^{1}+\ldots+v_{n} m_{a}^{n}}{m_{a}+m_{a}^{1}+m_{a}^{n}},
$$

where $m_{a}$ - pellet weight of the first fraction critical velocity, $g$;

$n$ - meant number of the sorted pellet fraction, unit.

Environmental resistance force was calculated using the formula [3]:

$$
R=\frac{k \rho A M v^{2}}{2},
$$

where $k$-aerodynamic resistance coefficient, which depends on the Reynolds number;

$A_{M}$ - Midship cross-sectional area, $\mathrm{m}^{2}$;

$\rho$ - air density, $\mathrm{kg} \cdot \mathrm{m}^{-3}$;

$v$ - velocity of pellet movement in the air flow, $\mathrm{m} \cdot \mathrm{s}^{-1}$.

Fertilizers are usually spread from centrifugal discs, which are disposed at an angle, thus the movement of the particles disposed at an angle must be explored. For example, the particle emitting plane is $x 0 y$ and the initial velocity is $v_{0}$. The angle of the throw is $\alpha_{0}$. Considering the gravity and 
aerodynamic resistance force performance, the movement differential or the particle equations in respect of the coordinate axes $O x$ and $O y$ can be evaluated [10]:

$$
m \frac{d v_{x}}{d t}=-k v_{x} ; 0 m \frac{d^{2} y}{d t^{2}}=-m g-k v_{y} .
$$

The particle flow factor is included in the equation. By solving and removing the time $t$ from the equation, we get:

$$
y=\left(\operatorname{tg} \alpha_{0}+\frac{g}{k_{0} v_{0} \cos \alpha_{0}}\right) x+\frac{g}{k_{0}^{2}} \ln \left(1-\frac{k_{0} x}{v_{0} \cos \alpha_{0}}\right) .
$$

The ballistic model of the particles can be projected according to the obtained equation. However, in order to project the organic granular model, the form of pellets and aerodynamic forces should be evaluated.

To create the pellet aerodynamic property model SOLIDWORKS software with the complement FlowSimulation was selected, which has a finite element solver. There it creates a 3D model of the pellets, physical - mechanical properties assigned [11]. Numerical analysis is performed by using the program integrated finite element solver. The MATLAB software was used to create the ballistic model. The program, which describes the pellet ballistic trajectory, was created by using the experimental results in MATLAB software [12]. Calculations were made on the basis of D.L. Antille research carried out by [4].

The investigation data were evaluated by the analysis of the variance method [13]. The arithmetic averages were set, their standard deviations and confidence intervals at a probability level of 0.95 .

\section{Results and discussion}

After examination of the organic fertilizer texture it was found that the diameter of the granular compost fertilizer was: Manure II $4.75 \pm 0.12 \mathrm{~mm}$, Manure I $5.28 \pm 0.8 \mathrm{~mm}$. The dominant length of the pellets for Manure II was 5-7.5 mm and for Manure I was 10 to $12.5 \mathrm{~mm}$ (Fig. 1).

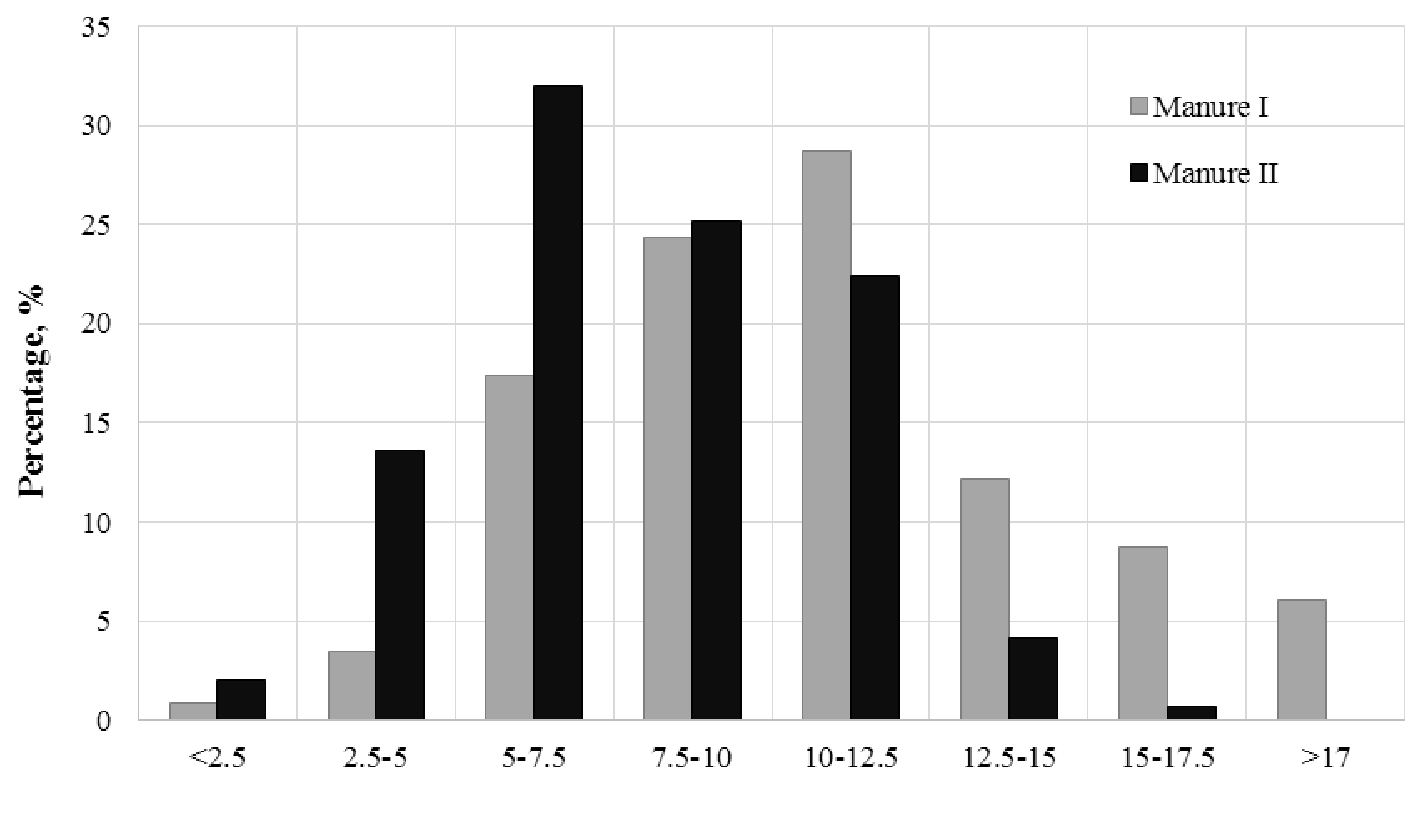

Pellet length, mm

Fig. 1. Distribution of dimensions of manure pellets

The investigation of the aerodynamic characteristics has shown the air flow velocity required for the pellet suction and it turned out that the Manure II pellets were hovered from a lower air flow velocity, while the Manure I pellets - were hovered from a larger air flow velocity (Fig. 2). 


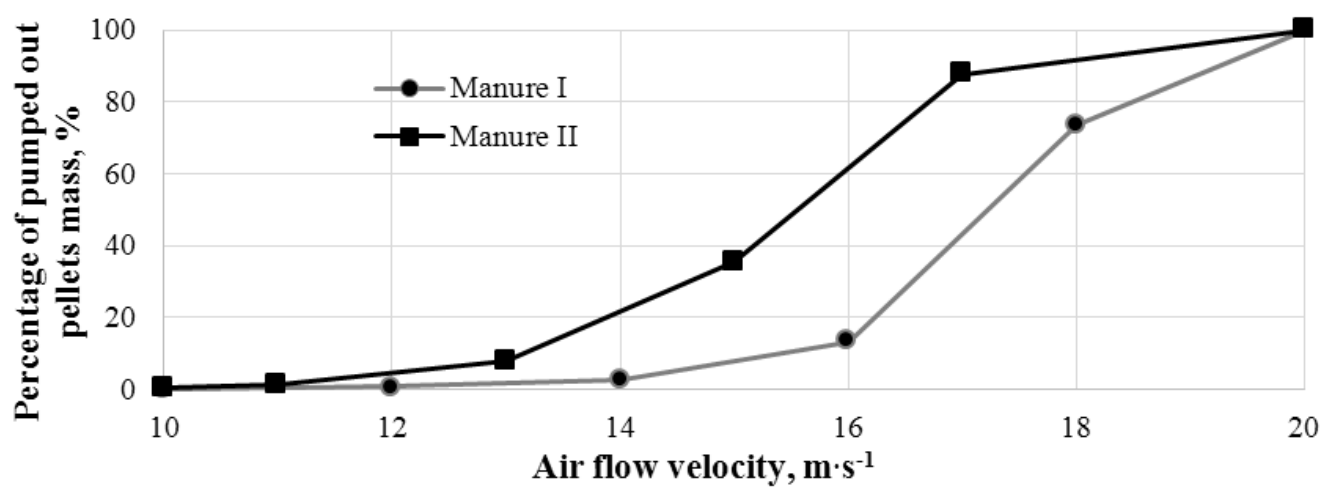

Fig. 2. Distribution of pellet mass according to air flow velocity

As it can be seen from the present results, most of the pellets are suctioned at $17-18 \mathrm{~m} \cdot \mathrm{s}^{-1}$ air flow velocity. The average critical pellet velocity is: Manure II $v_{k A v g}=16.3 \mathrm{~ms}^{-1}$, Manure I $v_{k A v g}=17.4 \mathrm{~ms} \mathrm{~s}^{-1}$ and the corresponding flow rate coefficient is $K_{\text {sAvg }}=0.37 \mathrm{~s}$ and $K_{\text {sAvg }}=0.32 \mathrm{~s}$.

After creation of the pellet design by the SOLIDWORKS Flow Simulation finite element (FEM) software, the force acting on the pellet landscape while it is moving at the appropriate velocity was calculated and the air resistance coefficient was set.

Table 2

The main aerodynamics characteristics

\begin{tabular}{|c|c|c|c|}
\hline Pellet size, mm & $\begin{array}{c}\text { Experimental aerodynamic } \\
\text { resistance coefficient }\end{array}$ & $\begin{array}{c}\text { Calculated aerodynamic } \\
\text { resistance coefficient }\end{array}$ & $\begin{array}{c}\text { Resistance } \\
\text { force, } \mathbf{N}\end{array}$ \\
\hline $5.28 \times 11.25$ & 0.82 & 0.88 & 0.00462 \\
\hline $4.75 \times 625$ & 0.91 & 0.97 & 0.00416 \\
\hline $\begin{array}{c}\text { Sphere, diameter } \\
55 \mathrm{~mm}\end{array}$ & - & 0.36 & 0.0018 \\
\hline
\end{tabular}

The model of the angle mounted pellet was created by using MATLAB (FEM) software and it imitates the sprinkled pellet spreader. While the model was created, the following parameters where chosen: the height of the spreader $h=0.75 \mathrm{~m}$, the velocity of spreading $v_{0}=20 \mathrm{~ms}^{-1}$, the angle of drop $\alpha=10^{\circ}$, the temperature of the air $20^{\circ} \mathrm{C}$. Mass of Manure I $m_{1}=0.32 \mathrm{~g}$ and Manure II $m_{2}=0.15 \mathrm{~g}$. Aerodynamic resistance force is recalculated every $1 \cdot 10^{-6} \mathrm{~s}$.

In Figure 3 it is shown that the drop distance is longer for the pellet Manure I at a large aerodynamic resistance force. The given results show that the drop distance remains longer due to the large mass of the pellet when the aerodynamic resistance coefficient of Manure I pellet is lower (1.1 times) and the Midship section is larger (1.23 times).

In Figure 4 dependency of aerodynamic resistance force on air flow velocity is shown.

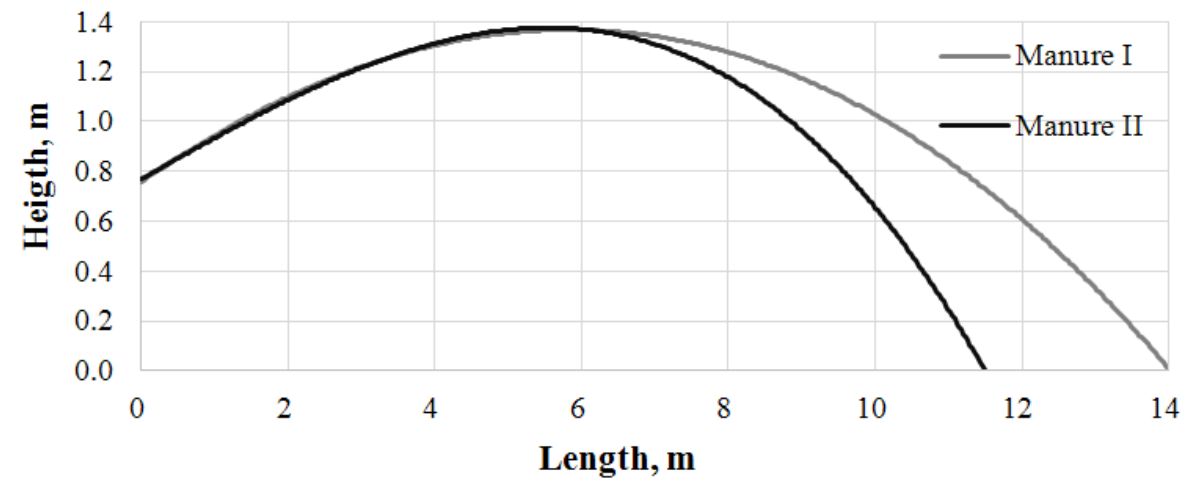

Fig. 3. Pellet trajectories at throw angle 


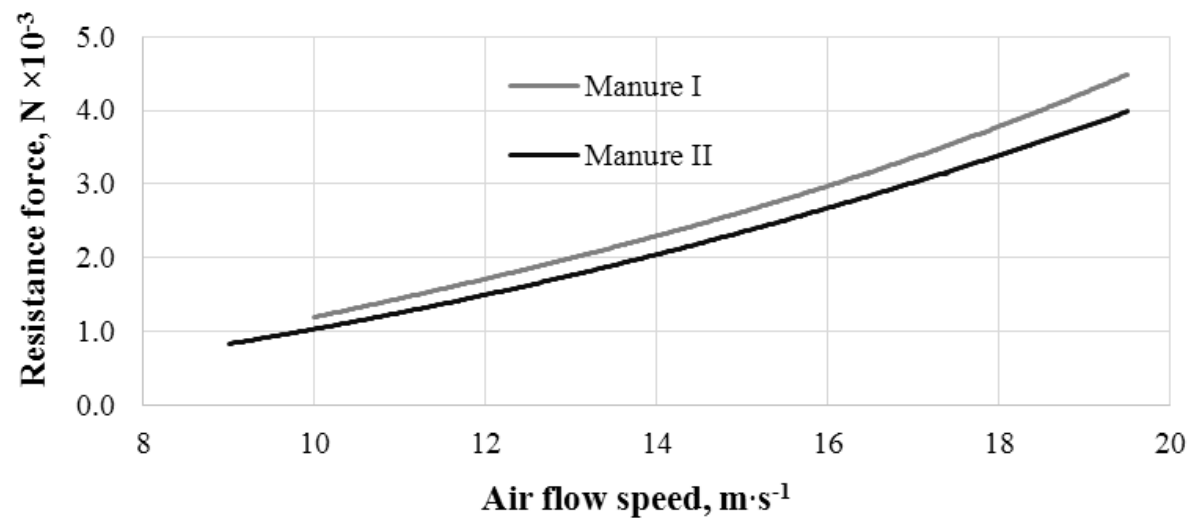

Fig. 4. Dependency of aerodynamic resistance force on air flow velocity

\section{Conclusions}

1. The study found that the pellet Manure II diameter is $4.75 \pm 0.12 \mathrm{~mm}$ and Manure I diameter is $5.28 \pm 0.08 \mathrm{~mm}$. By the instructions of the manufacturer, the diameter of these fertilizers is 4-5 $\mathrm{mm}$ and 5-6 $\mathrm{mm}$. It was set that the length of the pellet Manure II prevails between 5-7.5 mm and Manure I pellets prevail between 10 to $12.5 \mathrm{~mm}$ pellets.

2. The experimental studies have shown that the most of the granules $(60.1 \%)$ were vacuumed at $17.4 \mathrm{~m} \cdot \mathrm{s}^{-1}$ critical air velocity for larger diameter pellets Manure I. The overwhelming part of the smaller diameter pellets Manure II $(52.3 \%)$ were vacuumed at $16.3 \mathrm{~m} \mathrm{~s}^{-1}$ critical air velocity. It was found that the organic granular fertilizer flow rate coefficient depends on the pellet diameter. The lower flow rate coefficient (Manure I $K_{\text {SAvg }}=0.32 \mathrm{~s}^{-1}$ ) is for the larger diameter pellets, and for the smaller diameter pellets a larger flow rate coefficient is needed (Manure II, $K_{\text {sAvg }}=0.37 \mathrm{~s}^{-1}$ ).

3. After creation of the FEM pellet aerodynamic and ballistic models, the aerodynamic characteristics were received that can be used in selecting the spreading technological parameters.

\section{References}

1. Department of statistics [online] [25.11.2014]. Available at: http://www.stat.gov.lt/lt/ (In Lithuanian).

2. Nadzeikienè, J. Aplinkos apsaugos inžinerija (Environmental Engineering). Kaunas, 2012, p. 16-25. (In Lithuanian).

3. Pocius, A., Jotautienè, E., Pekarskas, J., Mieldažys, R., Jasinskas, A. Research of particle geometrical parameters and aerodynamic features of granular organic compost fertilizers//Engineering for rural development: 13th International Scientific Conference: proceedings, 2014, Vol. 13, pp. 401-406.

4. Antille D. L., Richard J. G. Determining the particle size range of organomineral fertilisers based on the spreading characteristics of the material. 2013, Kansas, Missouri, American Society of Agricultural and Biological Engineers, pp. 9-8.

5. Law S.E., Colier J.A. Aerodynamic resistance coefficients of agricultural particulate determined by elutriation //Transactions of the ASAE. - 1973.- № 5. pp. 918-922.

6. Aphale A., et al. Granular fertiliser particle dynamics on and off a spinner spreader. Biosystems Engineering 85.3. 2003, 319-329.

7. Petcu A. S., et al. Theoretical research regarding the working process of the fertilizers managing systems by centrifugation. Annals of the University of Craiova-Agriculture, Montanology, Cadastre Series 45.2, 2016, pp. 174-184.

8. Fertilizers II fertilizer characteristics. [online] [15.10.2015]. Available at: http://www.memon.nl/Portals/0/Leaflets \%20and \%20catalogues/UK/Technical \%20data \%20she et/TDS \%20Trąšos II.pdf (In Lithuanian).

9. Fertilizers I fertilizer characteristics. [online] [15.10.2015]. Available at: https://www.fermofeed.com/products/organic-fertilizers/organic-fertilizers-4-3-3 (In Lithuanian). 
10. Urba A. Dalelès balistika žemès ūkio mašinose (Particles ballistics in agricultural machinery). Kaunas, 2002, pp. 6 (In Lithuanian).

11. Mikulandric R., et al. Finite element for simulating mechanical behaviour of biomass residues. biosystems engineering 111.4. 2012, pp. 412-421.

12. Koko J., and Virin T. Optimization of a fertilizer spreading process. Mathematics and Computers in Simulation 79.10. 2009, pp. 3099-3109.

13. Kaminskienė J. Tikimybiu teorija ir matematinè statistika (Probability theory and mathematical statistics). LZUU, Akademija 2008, 78 p. (In Lithuanian). 